\title{
EL PERFIL OCULTO DE LA RAZÓN MODERNA
}

\section{SUSANA MAIDANA*}

\section{Introducción}

De la riqueza y multidimensionalidad que caracterizan a la razón moderna y a sus categorías, los agoreros del fin de la modernidad sólo advirtieron uno de sus variados perfiles: el de una razón dominadora que expandía su poder homogeneizador sobre la realidad natural y cultural. Una razón que procedía dogmáticamente, que prescindía de afectos, sentimientos, pasiones y se esforzaba en la búsqueda de la unidad, desoyendo las diferencias.

En estas líneas escudriño ese otro costado oculto, por debajo de los velos que solapan el verdadero significado de la modernidad.

\section{El perfil escéptico de la razón moderna}

Una de las notas sobresalientes de la filosofía moderna, en especial en los siglos XVI, XVII y XVIII, es la impronta del escepticismo, cuyo principal enemigo es el dogmatismo.

Richard Popkin en The bistory of Scepticism from Erasmus to Spinoza estudia el impacto del escepticismo griego en la filosofía moderna y señala que la crisis intelectual que sobreviene a la Reforma, juntamente con el redescrubrimiento del escepticismo antiguo de Sexto Empírico, en especial, de Montaigne, influyeron en la construcción de la matriz filosófica de la modernidad. Mientras los pensadores pirrónicos proponían suspender el juicio sobre el conocimiento cuando la evidencia sea injustificable, el escepticismo académico, por su lado, aseguraba que no era posible ningún conocimiento y formulaba una serie de argumentos para probar que ni los sentidos ni la razón proveían un conocimiento fidedigno, sino información tan sólo plausible.

\footnotetext{
*Profesora de la Universidad Nacional de Tucumán (sgoneme@tucbbs.com.ar).
} 
Si bien el término "escepticismo" fue entendido como incredulidad respecto de las doctrinas religiosas de la tradición judeo-cristiana, Karl Popper amplía la extensión del término a la problemática del conocimiento y adjudica al jónico Jenófanes el mérito de haber fundado la tradición filosófica escéptica a la que pertenecen Sócrates, Erasmo, Montaigne, Locke, Hume, Voltaire, entre otros. Pero aclara que habitualmente se confunde al escéptico con el que duda, sin embargo lo que lo caracteriza es la actitud crítica, a partir del reconocimiento de la finitud humana y de la imposibilidad de poseer un criterio infalible para determinar el criterio de verdad. Refiriéndose a las ideas de Jenófanes, el epistemológo vienés, dice: "No existe criterio de verdad; aún cuando hayamos alcanzado la verdad, nunca podemos dar certeza de ello"1. Por estas sendas escépticas transitaron Francisco Sánchez, Montaigne, Pièrre Charron, Francis Bacon.

Este es el camino que también siguió Descartes cuando inició su itinerario metafísico con el fin de socavar al escepticismo. En la primera de las Meditaciones Metafísicas se vale de argumentos escépticos para dudar del conocimiento sensible e intelectual. Ahora bien, es cierto que al hallar el cogito, reconstruye el edificio del saber con ciertos rasgos dogmáticos.

No sólo las críticas de Berkeley a las ideas abstractas; no sólo las críticas de Locke y Hume a la sustancia sino también la crítica de Kant a la metafísica nos pone delante ese otro ostro de la razón moderna que se autoexamina a sí misma y que es consciente de sus propios límites.

Las críticas a la razón no son propiedad fundamental de la postmodernidad, aun cuando es lícito reconocer que es a fines del siglo pasado cuando los cuestionamientos llegan a su punto más álgido. Por doquier se levantan las voces que denostan los usos y abusos de la señora razón; de reina, que gobernaba instaurando la igualdad entre los hombres, pasó a ser concebida como causante de los males que agobian al mundo.

La modernidad, según Richard Rorty, entre otros, fue cuestionada por destinar a la filosofía a ser un mero espejo de la naturaleza, al concebir a la mente como la superficie que transparentaba la realidad en sus intersticios más profundos y esta forma de concebir el conocimiento fue adjudicada sin

1 Popper Karl, "Sobre el conocimiento y la ignorancia" en En busca de un mundo mejor, Paidós, Barcelona, 1994, p. 62. 
más a la modernidad toda. Sin embargo, esta generalización olvida los intentos de la razón moderna de ponerse límites a si misma, imposibilitada de dar cuenta de la naturaleza objetiva de las nociones de causalidad, sustancia espiritual, ideas abstractas, únicamente explicables -en el caso del filósofo escocés- por vía de la creencia, disposición de la naturaleza humana que lleva a creer en aquello que la razón no puede explicar².

\section{David Hume y el otro rostro de la modernidad}

El programa filosófico humeano está comprometido con la búsqueda de la verdad, que lejos de ser absoluta, se enriquece en su andar crítico, trasciende las perspectivas dogmáticas y las creencias no fundadas. "Cualquier hombre juicioso e ilustrado -aclara Hume- percibe fácilmente el poco fundamento que tienen incluso sistemas que han obtenido el mayor crédito y que han pretendido poseer en el más alto grado una argumentación exacta y profunda" . Gracias a la crítica a las ideas centrales de la metafísica, Hume depura de soportes ontológicos a la filosofía, lo cual no significa eliminar las categorías metafísicas sino admitir que, si bien el hombre cree en ellas, no puede justificarlas racionalmente.

En la teoría política humeana, la sociedad se funda en el gobierno y éste en la opinión y en el consenso, que requieren como su condición la actitud de escuchar y atender la palabra de los otros. Knud Haakonsen en "The structure of Hume's political theory" en The Cambridge Companion considera que Hume creyó que la mayoría de las visiones de la sociedad y de la política que prevalecían en su tiempo, tenían sus raíces en las dos especies de Falsa Religión: la superstición y el entusiasmo, que son las notas que le adjudica a la Falsa Filosofía.

La misma actitud escéptica que lleva a Hume a negar fundamento ontológico y racional a las nociones claves de la metafísica tradicional es la que lo conduce a afirmar la imposibilidad de una norma universal que legisle

${ }^{2}$ La postura de Rorty olvida que la filosofía trascendental kantiana es también la contrapartida de la imagen especular de la mente, al investigar las condiciones a priori que hacen posible el conocimiento de los objetos.

${ }^{3}$ Hume David, Tratado de la Naturaleza Humana, Trad., notas y prólogo de Félix Duque, Técnos, Madrid, 1988, p. 33, XVII 
sobre los variados gustos. Lo bello y lo feo pierden estatuto ontológico y asumen diferentes significados según el receptor y según el juego de lenguaje en el que se inscriban y las reglas que compartan, sin por ello caer en un puro relativismo. Su mirada está puesta en la experiencia estética, en lo que el hombre experimenta en presencia de una obra de arte $y$, fundamentalmente, en el placer que su contemplación le depara.

Hume opera, pues, una verdadera inversión al desontologizar los conceptos valorativos estéticos, al colocar al espectador, al óítico, al sujeto, en el lugar del portador de los valores; e idéntico vuelco se produce en torno de los juicios éticos.

Hume, en el seno mismo de la Ilustración, produce el giro que va de la búsqueda de la belleza, como finalidad del arte, a la producción de la experiencia estética. Por cierto, ni la estética, ni la ética dan cuenta del mundo sino del sujeto, marcando un límite al racionalismo objetivista. De este modo va mostrando esa otra imagen de la modernidad, que da lugar a sentimientos y pasiones.

En el Ensayo "Sobre el origen y desarrollo de las artes y las ciencias"4 Hume considera que estas disciplinas sólo pueden desplegarse en un ambiente de libertad, alejado de actitudes autoritarias e intolerantes. Reconoce, de este modo, un condicionamiento cultural y social de las artes y de las ciencias en la medida en que toda forma de sometimiento es refractaria al refinamiento del gusto, tornando imposible el disfrute estético. Las diferentes artes son expresiones de diferentes formas de vida, de diferentes juegos de lenguaje, cada una acorde con sus distintas reglas de juego.

$\mathrm{El}$ arte refleja, en cierto modo, los tipos humanos de la sociedad, los problemas sociales, los regímenes políticos, estableciendo una relación dinámica entre la vida y la cultura, con lo cual Hume anticipa algunos de los planteos de Wittgenstein, en especial, su concepción de que las distintas formas de vida, las diferentes expresiones de la cultura se apoyan en un fondo de necesidades humanas, en la roca de la vida en sociedad 5 . Por cierto,

4 Hume David, La norma del gusto y' otros ensajos, Trad. María T. Beguiristáin, Península, Barcelona, 1989.

5 Ver L. Wittgenstein, Investigaciones Filosóficas, Crítica, Barcelona, 1988 (Parág. 217) 
tanto el filósofo escocés como el vienés pretenden acortar la distancia entre la vida y la filosofía.

En el caso de la tragedia, por ejemplo, sería de todo punto de vista imposible explicar el hecho de que un objeto en sí mismo horroroso y cruento desencadene placer estético. "Al corazón le gusta por naturaleza el ser conmovido y afectado"\%. Es el sujeto quien decide finalmente qué es lo bello o lo feo y ello explica que algo desagradable conmueva y deleite al espectador. "Todo el corazón del poeta está dedicado a despertar y mantener la compasión e indignación, la ansiedad y el resentimiento del auditorio. La complacencia de éste es proporcional a su aflicción, y nunca son tan felices como cuando lloran, sollozan y gritan para dar rienda suelta a su pesar y liberar sus corazones, henchidos de la condolencia y la compasión más delicadas"'.

Adelantamos que en las cuestiones estéticas el escepticismo humeano se acompaña de una perspectiva naturalista, por un lado, el escepticismo opera una doble negación: no solamente niega consistencia ontológica a las nociones estéticas sino, también, una posible fundamentación racional y, por otro lado, Hume, guiado por una impronta naturalista, admite de las valoraciones estéticas una justificación antropológica subjetiva, propia de la naturaleza humana.

En el ensayo Sobre la Norma del Gusto Hume observa la gran variedad de gustos de hombres de países y costumbres alejadas como de aquellos que comparten geografías, creencias y hábitos. El resultado de tal comprobación empírica lo conduce a afirmar que la inconstancia y contrariedad de los gustos impide su estandarización. Esta variedad e inconstancia se debe a la naturaleza peculiar de los juicios estéticos que se diferencian notablemente respecto de los cognoscitivos. Las diferentes respuestas que los hombres emiten sobre la belleza y la fealdad están causadas por el sentimiento y no obedecen a fundamentos racionales. Mientras todo sentimiento es verdadero en la medida en que no se refiere sino al propio sujeto que valora, en una suerte de autorreferencia; el juicio del entendimiento se refiere a un objeto que trasciende al sujeto. En el caso del gusto no hay conformidad entre el

\footnotetext{
${ }^{6}$ Hume, La norma del gusto y otros ensajos, ed.cit., p. 66.

${ }^{7}$ Hume, Ibid., p. 66.
} 
objeto y la facultad estimulada, lo que explica que un mismo objeto sea percibido como bello o como feo por diferentes sujetos. El juicio estético no se ocupa de las cosas en sí mismas sino de la relación y mutuo condicionamiento entre objeto y sujeto. En el caso de los juicios cognoscitivos solamente uno es verdadero, mientras que varios sentimientos, excitados por el mismo objeto, son todos válidos porque no representan lo que es realmente en el objeto.

Hume reinstala al hombre en la naturaleza y muestra que la razón no tiene en la vida humana el papel que la filosofía tradicionalmente le adjudicó.

"El escéptico" -conjuntamente con los ensayos referidos al platónico, al epicúreo y al estoico- contiene una aguda crítica a las ideas sustentadas por la tradición filosófica, que refuerza el significado del giro humeano y arroja mayor claridad sobre el tema que nos ocupa. Hume dice: "Si podemos depender de algún principio que aprendamos de la filosofía es éste, que pienso puede ser considerado cierto e indudable: no hay nada en sí mismo valioso o despreciable, deseable u odioso, bello o deforme, sino que estos atributos nacen de la particular constitución y estructura del sentimiento y afecto humanos. Lo que parece la más deliciosa comida a un animal resulta repulsivo a otro. Lo que afecta el sentimiento de uno con agrado produce desagrado en otro"s.

Más adelante refuerza estas ideas al afirmar que: “...la belleza y el valor son simplemente de una naturaleza relativa y consisten en un sentimiento agradable producido por un objeto en una mente concreta, de acuerdo con la peculiar estructura y constitución de esa mente"?.

La crítica de Hume a las teorías racionalistas y objetivistas no lo condenan, no obstante, a una postura relativista a secas, por el contrario, reconoce la presencia del objeto y la universalidad de ciertos valores estéticos que han alcanzado aprobación general. Algunos valores clásicos perduran en el tiempo a pesar de que, al mismo tiempo, sea denunciada la variedad e inconstancia de los gustos. El mejor ejemplo para explicar esta aparente

${ }^{8}$ Hume David, "El escéptico" en Disertación sobre las pasiones y" otros ensayos morales, Introducción, Traducción y Notas de J. L. Tasset Carmona, Anthropos, Barcelona, 1990, p. 231.

'Hume, Op.cit., p. 235. 
contradicción de nuestro autor es el de los catadores de vino del Quijote de la Mancha que ofrece en La Norma del Gusto. Hume admite que la uniformidad del gusto se debe no solamente a la configuración sana o enferma del sujeto y de sus órganos sensoriales, sino también a ciertas cualidades del objeto. Si bien la belleza consiste en un sentimiento agradable producido por un objeto en una mente concreta, lejos está de caer en una postura de corte idealista que niegue la presencia del objeto y de sus cualidades. Es precisamente el objeto, la vieja llave de hierro con la cuerda de cuero la que hizo que, en el momento de catar la bebida, uno percibiera cierto gusto a cuero y otro, a hierro.

No obstante la clave de bóveda para comprender las valoraciones estéticas reposa en la naturaleza humana, proclive a lograr cierto consenso en aquello que produce placer. La belleza no está en los objetos sino en la naturaleza humana misma, y si bien Hume considera que todos los hombres son capaces de sentir estéticamente, no todos explotan al máximo esta potencialidad natural común.

En La Norma del Gusto Hume nombra las características que debe tener la percepción estética adecuada para producir el juicio estético válido: 1. Ser de un refinamiento tal que perciba no solamente lo general de la obra, sino también sus partes. 2. No debe guiarse por la belleza superficial y florida. 3. Ser capaz de comparaciones entre distintos grados de excelencia. 4. Descubrir los propósitos que tiene la obra y observar si se han cumplido o nó. 5. Percibir la coherencia del todo a partir de la comprensión de las partes. Tales son las cualidades de un verdadero crítico.

Hume es, pues, un precursor de las estéticas contemporáneas al poner al sujeto, al crítico en el centro de reflexión estética, mas ello no significa que la razón no juegue papel alguno porque la descripción de la percepción estética adecuada y del sujeto capaz de llevarla a cabo no es algo del orden exclusivo del sentimiento. El verdadero crítico es aquél que, al cumplir con los requisitos señalados anteriormente, tendrá un sentimiento que pueda ser considerado como paradigma de todos los hombres. A esto se llega gracias a un conjunto de experiencias, habilidades y facultades en las cuales la razón es un requisito necesario, mas no suficiente.

La visión humeana sobre la ética es similar al tratamiento de los temas estéticos; parafraseando a Wittgenstein, podría afirmarse que según el autor del Treatise "ética y estética son lo mismo". 
Es cierto que quien intente despojar a la ética de fundamentos ontológicos no tiene más salida que recurrir al sujeto y a sus sentimientos, no obstante, David Fate Norton ${ }^{10}$ plantea que Hume no es un subjetivista moral sino un realista moral porque cree que los valores adquieren un estatuto objetivo y refuerza la idea de que también la razón juega un rol importante en la moral. En todo caso la razón es una esclava inteligente. La acción depende de principios estables de la mente, que constituyen el carácter personal. Hay valores que tienen cierta perdurabilidad y aprobación en general, así la justicia es más valorada que la injusticia del mismo modo que la obediencia a la autoridad o el respeto a las leyes. Es gracias al principio de la simpatía que apreciamos las acciones virtuosas, por ello comenta Hume: "Así, es manifiesto que la simpatía es un principio muy poderoso en la naturaleza humana, que tiene gran influencia en nuestro sentido de la belleza y que origina el sentimiento moral en todas las virtudes artificiales. Partiendo de estos puntos, cabe suponer que la simpatía origine también muchas de las restantes virtudes y que sea la tendencia al bien de la humanidad lo que haga merecedora de nuestra aprobación a una cualidad mental" 11.

\section{Conclusiones}

Así como las interpretaciones epistemológicas que se han hecho de la filosofía humeana han solapado sus investigaciones naturalistas $y$ malinterpretado su propuesta, una lectura de la modernidad en general y de la Ilustración, en especial, ha cargado las tintas en el imperio de una razón descarnada y fundamentalmente homogeneizadora que avasalla las particularidades. Sin embargo, la Ilustración se ha caracterizado también por la variedad y la discordancia; en ella convivían posturas materialistas como las de D'Holbach y La Mettrie con espiritualistas; inmoralistas como Sade y Helvetius con moralistas como Shaftesbury y Hutcheson, sin olvidar a los deistas como Collins y a los críticos de la religión como es el caso del mismo Hume.

La modernidad no tiene como su sesgo exclusivo el fluir de una razón, convertida en paradigma del acontecer natural y cultural; ello no

10 Ver Fate Norton David, "An Introduction to Hume's thought" en The Cambridge Companion to Hume, Cambridge University Press, USA, 1993, pp. 1-32.

${ }^{11}$ Hume, Tratado de la Naturaleza Humana, ed.cit., p. 575. 
significa, empero, negar el peso de la razón siempre y cuando tengamos presente el papel protagónico que asume la ciencia en la modernidad y la significación que tiene el conocimiento para los hombres y para la sociedad.

La obra Dialéctica de la Ilustración de Adorno y Horkheimer de 1944 es una prueba de esta visión de la modernidad que si bien reconoce la importancia del afán liberador de la razón ilustrada, la hace responsable, no obstante, del sometimiento a un nuevo tipo de barbarie bajo la égida de la "Ilustración" en virtud de haber producido un abismo entre el hombre y la naturaleza. La filosofía de Hume es una de las contrapruebas de esa sesgada visión. Las interpretaciones más clásicas de la filosofía humeana han acentuado la impronta escéptica de su programa filosófico y descuidado la naturalista, olvidando que sus esfuerzos estaban centrados en lograr una ciencia, cuyo objeto de estudio es la naturaleza humana, destruyendo de este modo a la "Falsa Metafísica".

Con el fin de reforzar nuestro planteo es ilustrativo el artículo "Hume y Nietzsche: Naturalists, Ethicists, Anti-Christians"12 en Hume Studies en el cual Craig Beam caracteriza a ambos pensadores como filósofos de la naturaleza humana y defensores de posiciones naturalistas, escépticas y antimetafísicas, a pesar de que tradicionalmente se los incluyó en corrientes filosóficas opuestas: a uno en la tradición neopositivista y al otro, en la existencialista y postmodernista. $\mathrm{Si}$ bien Craig Beam se refiere fundamentalmente a la ética $y$, en especial, a la concepción de virtud de Hume, definida como aquello que es útil y agradable a uno mismo y a los demás, considero que a la luz de sus textos, el mismo planteo puede ser aplicado a todo el programa filosófico humeano.

Por su parte, Suzana Parusnikova ${ }^{13}$ describe el estilo de Hume como renuente a ofrecer fundamentos ontológicos y epistemológicos fuertes,

12 Beam Craig, "Hume and Nietzsche: Naturalists, Ethicists, Anti-Christians" en Hume Studies, Volume XXII, Number 2. Edit. Hume Society, USA, November 1996, pp. 299-324

13 Parusnikova Suzana, "Against The Spirit of Foundations: Postmodernism and David Hume" en Hume Studies, Ed. Hume Society, Vol.XIX, Number 1, April 1993, pp. 1-17. 
evitando los hechizos de las universalizaciones, tan caros al discurso de la metafísica clásica.

En esta misma línea argumentativa, David Fate Norton, ${ }^{14}$ entre otros, sostiene que el escepticismo de Hume muestra que el conocimiento no comparte nada de la fundamentación firme que los cartesianos le adjudicaron. No obstante, su posición no es meramente destructiva sino también constructiva por cuanto la nueva ciencia de la naturaleza humana es el fundamento de todas las ciencias y abarca a la moral, la política y la estética. Así como la moralidad existe porque hay tendencias naturales humanas, del mismo modo, existe la esteticidad, únicamente explicable por la condición natural del hombre. El papel protagónico que Hume le otorga a los sentimientos en sus ensayos da cuenta de estas afirmaciones.

Hume es, pues, un paradigma de la actitud filosófica que, sin rechazar a la razón, deja lugar al sentimiento, a las creencias, en suma, a la naturaleza humana.

Resulta sugerente pensar cómo en el seno mismo de la modernidad estaban ya anunciadas las críticas a sus propias categorías -sujeto, causalidad, sustancia, ideas abstractas, razón absolutizadora- que dos siglos más adelante habrían de constituir los temas centrales en algunos ámbitos filosóficos.

Lo interesante es el hecho paradójico en una primera lectura- de que esa razón moderna, tan narcisísticamente enamorada de sí misma sea, al mismo tiempo, tan dobrosamente consciente de sus propios límites.

Quizás, sería oportuno decir - parafraseando a Kant- que la razón moderna era el tribunal encargado de juzgarse a sí misma, despojándose de falsas aspiraciones. Es precisamente este perfil de la modernidad lo que sus detractores ocultaron y que urge desocultar en aras de reivindicar la vigencia de la razón y de la ciencia moderna en un mundo amenazado por el nihilismo.

Quisiera concluir con Villoro, cuando expresa: "Los países del Tercer Mundo entramos en la modernidad en el momento en que empieza a ponerse en crisis. Lo cual nos coloca en una situación privilegiada: podemos ver 'época moderna' tanto en sus inicios como en sus fines, antes de

14 Ver cita 10. 
aventurarnos plenamente en ella. Estamos frente a una responsabilidad aún inédita. Podemos evitar el camino que otros hollaron. Podemos elegir lo que fue avance y liberación en el proyecto moderno e intentar prevenir sus consecuencias indeseables" 15 . Valgan estas líneas como una defensa de la razón moderna en tiempos de crisis.

\title{
Resumen
}

Así como las interpretaciones epistemológicas que se han hecho de la filosofía humeana han solapado sus investigaciones naturalistas y malinterpretado su propuesta, una lectura de la modernidad, en general y, en especial, de la Ilustración, ha cargado las tintas en el imperio de una razón descarnada y fundamentalmente calculadora, empeñada en un dominio técnico de la naturaleza y de los hombres. En estas líneas escudriño, por debajo de los velos que solapan el verdadero significado de la modernidad, ese otro costado oculto. Los escritos estéticos de Hume constituyen el hilo conductor de la búsqueda.

Palabras claves. "Hume", "razón moderna".

\begin{abstract}
While the epistemological interpretations made of Hume's philosophy have evaded his naturalistic investigation and misinterpreted his ideas, a reading on modernity, both in general and, mainly, on illustration has gone deep into the empire of the stark and fundamentally calculating reason, determined in a technical domain of nature and men. I investigate, under the veils obscuring the true meaning of modernity, that hidden side. The focus of this inquiry is Hume's aesthetic works.

Key Words: "Hume", "modern reason".
\end{abstract}

${ }^{15}$ L. Villoro, El pensamiento moderno. Filosofia del Renacimiento., FCE, México, 1992, p. 104. 